\title{
USING THE ANALYTIC HIERARCHY PROCESS
}

\section{IN UNIVERSITY RANK AND TENURE COMMITTEE DECISIONS}

\author{
Cynthia Busin Nicola \\ School of Management \\ Carlow University \\ Pittsburgh, PA, USA \\ E-mail: cmnicola@carlow.edu \\ Enrique $\mathrm{Mu}$ \\ School of Management \\ Carlow University \\ Pittsburgh, PA, USA \\ E-mail: emu@carlow.edu
}

\begin{abstract}
This study develops a model for rank and tenure decisions using an AHP ratings model. Up to know decisions have been made by means of meeting discussions among the rank and tenure members. This decision model, based on current approved policies by the committee, is expected to provide objectivity and transparency to the rank and tenure committee decisions.
\end{abstract}

Keywords: rank and tenure, university promotion decisions.

\section{Introduction}


Carlow University is a small, catholic, private university in Pittsburgh, PA. Currently, all decisions in promotion and tenure are handled by a committee of elected faculty, without any specific association with School or discipline area. Faculty applicants submit a detailed portfolio of evidence to the Rank and Tenure Committee in the fall with review and deliberations conducted by the middle of January each academic year. Applicants organize evidence according to three major sections of responsibility: teaching, service and leadership, and scholarship. Sub-dimensions in each of these areas are chosen by the applicant in accordance with the "Faculty Growth and Responsibilities" document approved by the University Faculty Assembly in May, 2013. Current committee deliberations take place without weighting any particular factor or section, even though the area of teaching is listed as the primary area of responsibility.

\section{Literature Review}

This project is in the form of a case study. Documents reviewed (Boyer, 1990; Carlow University, 2013; Stevens, 2003) were those provided by the Rank and Tenure Committee. The study will examine the current documents and process of decision making with a resulting prototype for using the Analytic Hierarchy Process in the future.

\section{Hypotheses/Objectives}

Since there is a possible "disconnect" between what the "Faculty Growth and Responsibilities" document guidelines intention and the actual deliberation/recommendation process, this study will provide a decision-making model proposal for Rank and Tenure Committee deliberations beginning in the academic year 2014-2015 at Carlow University.

\section{Research Design/Methodology}

The AHP model is based on information from Rank and Tenure Committee documents, portfolio review process and the deliberation meetings. Authors $\mathrm{Mu}$ and Nicola are current and/or past members of Rank and Tenure and use their experience to inform proposing an AHP ratings model, based on the portfolio criteria provided to faculty.

\section{Data/Model Analysis}


ISAHP Article: Nicola, Mu/AHP in University Rank and Tenure Committees. International Symposium of the Analytic Hierarchy Process 2014, Washington D.C., U.S.A.

\section{Limitations}

The Rank and Tenure Committee consists of eight members, six of whom are regular members for multi-year terms and two of which are alternates who serve one-year terms. The study consisted of the experiences of two members of this standing committee, which limited opinions on the adoption of a decision-making model. If there were more time to conduct the study, it would have been helpful to involve the entire committee in the process of developing the AHP model. Conflicting faculty schedules did not permit this to happen at this time. Likewise, it is uncertain how precedent using subjective means/opinion will factor in to the adoption of a decision-making model.

\section{Conclusions}


ISAHP Article: Nicola, Mu/AHP in University Rank and Tenure Committees. International Symposium of the Analytic Hierarchy Process 2014, Washington D.C., U.S.A.

The prototype developed will be presented to the Rank and Tenure Committee to be used for deliberations for the 2014-2015 academic year. The AHP model provides a more objective way to discuss the merit of faculty going for promotion in rank or for faculty requesting tenure. Using the model is in line with the intention of the "Faculty Professional Growth and Responsibilities" (Carlow University, 2013) guidelines.

\section{Key References}

Boyer, E. (1990). Scholarship reconsidered: Priorities of the professoriate. Carnegie Foundation Special Report.

Carlow University (2013). Faculty professional growth and responsibilities. Carlow University Faculty Assembly: Rank \& Tenure Committee.

Saaty, T.L., \& Peniwati, K. (2007). Group decision-making: Drawing out and reconciling differences. Pittsburgh, PA: RWS Publications.

Stevens, M. (2003). Mercy higher education: Culture and characteristics. Paper presented at the Conference for Mercy Higher Education 2008.

\section{Appendices}

